\title{
Response to paper by Tsioufis et al.
}

\author{
Casril Liebert $^{1}$ (D) $\cdot$ Roshan Patel $^{1} \cdot$ Ali Kirresh $^{1} \cdot$ Mahmood Ahmad $^{1}$
}

Received: 19 June 2020 / Accepted: 29 June 2020 / Published online: 10 July 2020

(c) Springer-Verlag GmbH Germany, part of Springer Nature 2020

Sirs:

We were interested to read Tsioufis et al.'s [1] study which demonstrated a significant decrease in patients presenting with myocardial infarctions (MI) during the COVID-19 pandemic. Daily attendance to the Emergency Cardiology Department of a tertiary hospital in Athens, Greece was 41.1\% lower in March 2020 and 32.7\% lower in April 2020, as compared to January $2020(p<0.001)$. However, Tsioufis et al.'s study was limited to a single hospital which did not admit COVID-19 patients and, therefore, the results may not be generalisable.

Gupta et al. [2] demonstrated a significant decrease in cardiac catherization laboratory procedural volumes in the New York metropolitan area during the COVID-19 pandemic. Prior to March 2020, 57\% of institutions estimated their average monthly percutaneous coronary intervention (PCI) volume to be greater than 150 , while $70 \%$ expected there to be less than 25 cases in April 2020. These findings are in keeping with Tsioufis et al.'s and, furthermore, Havenon et al. [3] described similar results throughout the USA in 36,551 acute coronary syndrome (ACS) patients. Hospitalizations with any discharge diagnosis of ACS in March 2020 decreased by 7.5\%, compared to March 2018 and 2019. Interestingly, there was a disproportionate reduction in PCI numbers of $14.7 \%$ which likely reflects a loss of both elective and emergency work.

Hammad et al. [4] demonstrated that the reduction in cardiovascular presentations also extended to 'non-hotspot' regions of COVID-19. Of the 143 ST-elevation myocardial infarctions (STEMIs) presenting between January 1st 2020 and April 15th 2020, patients in the post-COVID-19 period had significantly lower ejection fractions (EF) at admission compared to the pre-COVID-19 period (EF 45 vs. $50 \%$, respectively, $p=0.015$ ). This supports the notion

Casril Liebert

casril.liebert.19@ucl.ac.uk

1 University College London Medical School, London, UK that patients may have delayed seeking medical attention, and Tsioufis and colleagues may wish to report the average pre- and post- COVID-19 EF in their STEMI cohort to see if they have similar findings.

Hammad et al. [4] also demonstrated that patients in the post-COVID-19 group were more likely to present with a greater than 12-h delay and these patients had increased rates of high-risk features including a higher peak troponin (58 [9-73] vs. 8.5 [4-10] $\mathrm{ng} / \mathrm{ml}, p=0.03$ ) and EF of less than $40 \%$. Upon questioning, $27 \%$ of patients reported that they avoided hospital due to anxiety surrounding COVID$19,18 \%$ believed that their symptoms were COVID-19 related, and 9\% did not want to burden the hospital during the pandemic. This demonstrates the need for a broad public health campaign to prevent these late clinical presentations. Tsioufis and colleagues may wish to assess the longer-term implications of the reduced ACS presentations during the COVID-19 pandemic on long-term morbidity and mortality.

\section{References}

1. Tsioufis K, Chrysohoou C, Kariori M et al (2020) The mystery of "missing" visits in an emergency cardiology department, in the era of COVID-19.; a time-series analysis in a tertiary Greek General Hospital. Clin Res Cardiol. https://doi.org/10.1007/s0039 2-020-01682-1

2. Gupta T, Nazif TM, Vahl TP et al (2020) Impact of the COVID-19 pandemic on interventional cardiology fellowship training in the New York metropolitan area: A perspective from the United States epicenter. Catheter Cardiovasc Interv. https://doi.org/10.1002/ ccd.28977(published online ahead of print, 2020 May 16)

3. de Havenon A, Ney J, Callaghan B et al (2020) A rapid decrease in stroke, acute coronary syndrome, and corresponding interventions at 65 United States Hospitals following emergence of COVID-19. medRxiv. https://doi.org/10.1101/2020.05.07.20083386

4. Hammad TA, Parikh M, Tashtish N et al (2020) Impact of COVID-19 pandemic on ST-elevation myocardial infarction in a non-COVID-19 epicenter. Catheter Cardiovasc Interv. 2020: https ://doi.org/10.1002/ccd.28997 (published online ahead of print, 2020 Jun 1) 